\title{
ME CHAMAM RUA, POPULAÇÃO, UMA SITUAÇÃO: OS NOMES DA RUA E AS POLÍTICAS DA CIDADE
}

\author{
ME LLAMAN CALLE, POBLACIÓN, UNA SITUACIÓN: LOS NOMBRES \\ DE LA CALLE Y LAS POLÍTICAS DE LA CIUDAD

\section{THEY CALL ME STREET, POPULATION, A SITUATION: STREET NAMES AND CITY POLICIES}

\author{
Mateus Freitas Cunda ${ }^{1}$ e Rosane Neves Silva ${ }^{1}$
}

${ }^{1}$ Universidade Federal do Rio Grande do Sul, Porto Alegre,/RS, Brasil

\begin{abstract}
RESUMO: O texto acompanha algumas categorizações criadas para nomear os habitantes da rua, ao ponto de chamarmos no Brasil por "População em Situação de Rua". A categoria expressa um dos limites da pobreza urbana e, de modo transversal, a expropriação burguesa, branca e patriarcal. No plano urbano, é resultado dos movimentos de dispersão, segmentação, periferização e rualização da cidade. Os habitantes da rua, por outro lado, animam um sistema filantrópico que cria seus códigos e técnicas de enquadramento e salvação. Apesar das nomeações, uma vida perene e incapturável surge das ruas, com estratégias de sobrevivência e proteção que desafiam a maldição dos nomes e as políticas da cidade.
\end{abstract}

PALAVRAS-CHAVE: População em situação de rua; Políticas públicas; Pobreza urbana.

ABSTRACT: The text follows some categorizations created to name the homeless, to the point of being called in Brazil "População em Situação de Rua” (Population in a Homeless Situation). Said category expresses one of the limits of urban poverty and, in a transversal way, the bourgeois, white and patriarchal expropriation. At the urban level, it is the result of the city's dispersion, segmentation and peripheralization movements. The homeless, on the other hand, animate a philanthropic system that creates its codes and techniques of framing and salvation. Despite the nominations, a perennial and uncapturable life emerges from the streets, with survival and protection strategies that defy the weight that the names given to them bring, as well as city policies.

KEYWORDS: Homeless population; Population in a homeless situation; Public policy; Urban poverty.

RESUMEN: El texto sigue algunas categorizaciones creadas para nombrar a la gente que vive en las calles, hasta el punto en que los llamamos en Brasil "Población en situación de calle". La categoría expresa uno de los límites de la pobreza urbana y, de manera transversal, la expropiación burguesa, blanca y patriarcal. A nivel urbano, es el resultado de los movimientos de dispersión, segmentación, ‘periferización’ y ‘callerización’ de la ciudad. Los habitantes de la calle, por otro lado, animan un sistema filantrópico que crea sus códigos y técnicas de encuadre y salvación. A pesar de los nombres, una vida perenne e insondable emerge de las calles, con estrategias de supervivencia y protección que desafían la maldición del nombre y las políticas de la ciudad.

PALABRAS CLAVE: Población en situación de calle; Políticas públicas; Pobreza urbana. 


\section{Introdução}

Os moradores das ruas, ou habitantes da rua, como refere Cláudia Turra Magni (2006), são tão diversos em sua composição, que seria difícil criar perfis sobre modos de vida ou hábitos. Em todo caso, essa é uma tentativa reiterada dos saberes acadêmicos e científicos. Buscaremos mostrar o quanto esse público já foi nomeado, cada nome com seus enquadres e critérios de classificação, geralmente construídos ao revés: pela falta de crença, pela falta de comida, pela falta de trabalho, pela falta de domicílio, pela falta de família.

O texto apresentará uma série de nomeações que se formam em torno do habitante da rua, elencadas, não ao acaso, numa política estética que enuncia o "não-lugar" na cidade, animado pela força dos enunciados dos poderes (filantrópicos, policiais, médicos, psicológicos) que nele atuam. Esse artigo trará alguns desses nomes construídos pela normativa urbana, de modo a questionar a amálgama de uma categorização sobre as pessoas que habitam essa margem da cidade.

\section{Nômade}

Marie-Ghislaine Stoffels (1977) refere que desde a Grécia Antiga há registro de ondas de pessoas itinerantes que não se enquadravam dentro do sistema de hierarquização das cidades. Tais pessoas tinham uma condição diferente a dos escravos - submetidos à escravidão por filiação, endividamento ou crime de guerra -, a dos comerciantes estrangeiros - que estabeleciam seus negócios na cidade, mas não ingressavam nas discussões políticas da polis -, e também da condição das pessoas pobres - maioria populacional tanto em Atenas quanto em Roma, e que podiam, por filiação ou posto de trabalho, serem cidadãos. Os nômades, conta Cláudia Magni (2006), em referência à pesquisa de Stoffels, eram pessoas que haviam sido expulsas de suas comunidades pela expropriação alheia, que fugiam da escravidão e que não se perfilavam na divisão do trabalho. Nas cidades, eram identificados como mendigos ou indigentes: "o miserável que não fosse escravizado ou que desertasse do regime de escravidão não teria outra forma de sobreviver que a mendicância e a vadiagem na cidade, alternando o pedido com pequenas tarefas” (Magni, 2006, p. 16).

A identidade fugidia desse personagem antigo das ruas não era, todavia, alvo de uma política dos soberanos. Sua própria condição marginal não permitia ancoragem nas grandes cidades do mundo antigo, o destinando ao ostracismo, à novas odisseias ou à morte diretamente.

\section{Desgraçado}

Lewis Mumford (1998) diz que a filosofia cristã trouxe um contorno à desgraça dos tempos de guerra e uma insegurança que marcaram a dissolução do Mundo Antigo. Sustentado na ênfase ao "pecado, dor, doença, fraqueza, morte", deu sentido à civilização que se encontrava em franca desintegração: "em vez de fugir às negras realidades de seu tempo, o cristão as abraçava, fazendo de boa vontade o que os pagãos ociosamente evitavam" (Mumford, 1998, 267). Ao pregar o preceito de igualdade dos seres humanos, permitia que independentemente da posição na cidade, da estética do corpo, da beleza ou da riqueza da pessoa, a pessoa poderia se converter ao Deus uno que horizontalizava a 
todos. A oposição entre a Cidade de Deus e a Cidade dos Homens, presente na obra de Santo Agostinho e constante nos textos de São Paulo, reafirma o lugar da humildade, opondo os valores espirituais aos terrenos.

Essa compreensão acerca da vida mundana aproximou a nova religião dos pobres e vulneráveis. Uma “aliança ética”, diz Richard Sennett (2008), sustentada na imagem do Cristo em chagas, na valorização do sofrimento e do sofredor. Nesse contexto, a figura do pobre, indigente, mendigo e doente ganhou um lugar de destaque. A prática da assistência fraterna "redimia as ignomínias da fome, da doença e da penúria, tornando-as uma ocasião de camaradagem e amor" (Mumford, 1998, p. 268). Sustentado pela filiação à proteção monástica, cada ovelha cuidava de si como do próximo, gerando uma corrente que, pelos degraus do catolicismo, chegaria ao Pai. Na cidade de Deus, Deus é amor. E o amor à humanidade, conforme o dicionário, chama-se Filantropia.

A apologia à pobreza e ao desapego dos bens materiais era sustentada, por outro lado, através do trabalho cotidiano dos frades e religiosos. As ordens mendicantes, iniciadas por São Francisco e Santo Domingos, no século XIII, produziram uma reformulação na técnica filantrópica, tanto na concepção espiritual quanto na intervencionista. Surgem nessa baila instituições que subsistiam estritamente dos donativos, acusando que precisavam apenas o mínimo para uma vida valorosa. A empresa era feita com paixão, num esforço coletivo.

Esse sistema filantrópico aprofundou o conhecimento sobre as mazelas das cidades. As irmandades de frades e freiras com caráter assistencial se multiplicaram na Idade Média, especializando o olhar sobre os diversos tipos de incapacidades. Acolhiam, no afã da fé, os viajantes, pessoas sem teto, crianças abandonadas, doentes desconhecidos e insanos (Sennett, 2008). A terapêutica previa o trabalho como condição de dignidade, condicionando o acesso ao alimento à produtividade, pois, conforme consta na Regra não bulada da ordem dos frades menores, capítulo $7^{1}$, "Diz o profeta: 'Comerás os trabalhos dos teus frutos; és feliz e estarás bem” (Sl 127, 2). E o apóstolo: 'Quem não quer trabalhar, não coma' (cfr. 2Ts 3, 10)"

\section{Mendigo}

Embora quisesse desmantelar a lógica de riqueza da cidade, as ordens mendicantes cabiam bem para a gestão dos problemas municipais e, de maneira quiçá incalculada, compondo a função assistencial do Estado. Lewis Mumford (1998) entende que o pensamento franciscano não tinha grandes chances de prosperar em outra época, referindo que tempos antes outras ações semelhantes foram consideradas heresias, perseguidas e sepultadas. $\mathrm{O}$ papa João XXII, contudo, em vez de abolir a "heresia”, segundo Mumford (1998, p. 347):

insistiu em fazer da ordem franciscana um instrumento do poder papal e assegurou sua subordinação e mesmo sua subversão interior, encorajando um pesado investimento em convenientes edificações conventuais, no próprio lugar onde nascera a nova ordem, pois não há modo mais eficiente de matar uma ideia do que "materializá-la" bem cedo.

\footnotetext{
1 Recuperado de http://www.capuchinhos.org.br/procasp/franciscanismo/escritos-de-sao-francisco/ proposta-de-vida/regra-nao-bulada/regra-nao-bulada-introducao
} 
Frente ao sistema de caridade nascido na Idade Média, a figura do "mendigo" se especializou ao ponto em que ser um assistido era quase como uma profissão (Castel, 2015). Sua existência era mantida nos limiares do corpo santificado da caridade e do corpo ocioso para o trabalho: entre o santo e o vadio se abriu um vasto campo de dúvidas e imprecisões. $\mathrm{O}$ "mendigo inválido" era definido em parte por sua condição corporal: "magro, cego, chagado, frequentemente coxo" (Mollat, 1989); mas também por sua condição moral, com o peso de sua desgraça, com uma postura que acuse a submissão e a vergonha de não poder trabalhar.

Como o público de desassistidos era bastante abrangente, fez-se uma criteriosa classificação dos sujeitos que seriam atendidos por cada municipalidade. A partir do teste de veracidade, provado o merecimento, o indivíduo era incorporado em uma lista de carentes, fazendo jus a uma determinada benesse, conforme avaliação da paróquia (Castel, 2015). Eram alvo, especialmente, aqueles indivíduos que apresentassem uma dependência estrita ao tecido social, como idosos, deficientes, órfãos e insanos. De acordo com a inaptidão apresentada, era tentada providencialmente a reintegração da pessoa no campo das relações de troca. Não sendo o problema corrigível, a pessoa ficava a cargo dos recursos senhoriais - limitados - e à mercê da disposição familiar para acolhê-la - mormente, ausentes. Em muitos casos, nem família, nem senhoril, nem trabalho sustentavam a filiação em uma rede de proteção. Não raro, o sujeito passava para um estado de isolamento social, entregue à própria sorte. Esse personagem desassistido se somava à massa de pessoas despossuídas, andarilhas ou nômades que ficavam fora do sistema de caridade, num fluxo de peregrinação, sem ancorar nas cidades, habitando as estradas ociosas e os campos desabitados.

\section{Vagamundo}

Na Europa e nas cidades inventadas na América, o progressivo desatrelamento à subsistência campesina provocou um efeito de desamparo importante, transpondo a posição de servidão no campo para a vivência da pobreza na cidade. Nos infindáveis movimentos do êxodo rural, se forma uma nova urbanidade, e as cidades se tornam um lócus de possibilidades de proteção mais provável que no campo. Não tardou para existir superpopulações em torno da oferta de trabalho, margeando o crescente comércio livre. No século XVII, a miséria já era parte natural da urbe: "já se calculou que nada menos de uma quarta parte da população urbana consistia de marginais e mendigos” (Mumford, 1998, p. 468). A população formada pelos camponeses retirantes, pelos frequentes nômades e andarilhos, por estrangeiros, comerciantes falidos e desempregados formava um invólucro estigmatizante, que permitiu uma gradação sem limites claros entre a ociosidade, a debilidade, a pobreza e o crime.

Sob a mácula da improdutividade e do perigo, a figura do "vagabundo" adquire nesse nevoeiro uma afirmação do que precisava, sem misericórdia, ser erradicado. Segundo Robert Castel (2015), esse personagem cumpre a dupla desfiliação: dos vínculos familiares ou comunitários; da inaptidão para o trabalho. Personificado num contorno híbrido, ladeado pelo mendigo válido, pelos profissionais de má-reputação (malabaristas, cantores, exibidores de curiosidades, arrancadores de dentes), pelos jogadores, as prostitutas, os beberrões, os ladrões, o "vagabundo" se consolidou com a regulamentação do trabalho nas cidades, mas sua fama se afirmou pela associação de diversas existências desadaptadas à ordem vigente. O historiador Bronislaw Geremek (1995), ao pesquisar os "vagabundos" e miseráveis na literatura europeia, no período de 1400-1700, fala da criação de uma "literatura do malandro", disseminando a imagem do engano, da farsa, do desvio. Óperas, peças 
de teatro, poesias, anedotas, exaltaram a figura do "vagabundo" como um personagem típico das cidades. As narrativas afirmam outrossim a periculosidade de sua existência, marcando a diferença de sua condição e seu papel na história: "seu mundo ficava à parte, bem delimitado em termos de espaço, de organização social e por fim de regras morais e elementos culturais, que os separavam do resto da sociedade" (Geremek, 1995, p. 42). Destacam-se nessa literatura pessoas como: menestréis, contadores, bardos, "mercadores ambulantes que vendem produtos falsos ou proibidos", falsos mendigos, falsos doentes (que simulam feridas, lesões, comiam sabão para fazer sangrar o nariz, etc.), peregrinos fingidos, aleijados simulados, falsos frades mendicantes, pequenos ladrões, ladrões de cavalos, ladrões de feira, arrombadores, jogadores de dados, famílias nômades, ex-prisioneiros, vendedores de falsas relíquias religiosas, loucuras fingidas (como rasgar a roupa ou andar com uma corrente), cegos (pela vontade de Deus, em decorrência de má conduta), etc. Frente a tal generalidade, Michel Mollat (1989) identifica que a melhor tradução da vagabundagem seria o "Sans Aveu, sem-moralidade", que englobaria os focos centrais das medidas de controle: o sem-domicílio, o sem-trabalho, o "demeurant partout-que mora em toda parte", o "sans feu ni lieu - sem fogo nem lugar".

Uma variedade de atitudes suspeitas foram precisamente delineadas em torno de tais personagens, descrevendo-os tanto para criar uma diferenciação mínima entre o bandido e o mendigo, quanto para estabelecer, em primeiro plano, uma polícia de vigilância para a pobreza urbana. O "vagabundo" - antítese do homem econômico - compõe a figuração social da desvalia, da indigência, incluído dentro de um circuito marginal no qual estavam também os sujeitos da desrazão, os trabalhadores mais desprotegidos do sistema patriarcal e laboral, os idosos, os órfãos, os deficientes físicos, os pobres doentes. Todos sem ancoradouro.

\section{Rueiro}

A arquitetura das cidades modernas buscou, em contraponto ao ambiente público, uma assepsia do tecido urbano. Apostando na linearidade das ruas e na verticalização dos prédios de poder, a cidade voltava-se para dentro de si mesma: as edificações buscavam a privatização do espaço. A rua, diz Mumford (1998), passou a ser a unidade de planejamento econômico e social. Do centro à periferia, o espaço público se torna o meio de transição, destinando o transeunte para logo adiante, num longo andar. Aos veículos motorizados, a circulação é aprimorada de modo que não houvesse interrupções entre um ponto e outro. Com rapidez, a cidade geometrizada teve suas distâncias diminuídas pela velocidade das grandes avenidas e, com tal movimento, cumpria o efeito de invisibilizar os peregrinos do caminho. Para Richard Sennett (2008), recuperando a história da urbanização de Nova York, o crescimento produtivo da cidade foi concomitante com a gestão das massas populacionais. A dispersão da cidade pelas artérias até os pontos inabitados favoreciam, de um lado, o fluxo de riquezas ao centro econômico, e de outro ampliaram as bordas do território urbano. O desenho da cidade reitera sua função econômica. No centro, a padronização da vida produtiva consistia, a rigor, em desfazer as diversidades. Na periferia formam-se aglomerações distantes da maior conurbação, verdadeiros aldeamentos. Sennett conversa com autores como Roland Barthes e Erving Goffman para sustentar que o modelo burguês afetou cada unidade da cidade, criando imagens que recobriam o vivido de modo a reconhecer, até pelo andar do corpo, qual a posição do sujeito dentro da urbe. A existência na cidade fica, desse modo, atrelada à possibilidade de diferir de um determinado conjunto de imagens identitárias. 
A rua, nesse desenho, se torna um não-lugar. É o espaço do movimento, do superficial, das trocas mínimas, do que Goffman chama de "desestimulação defensiva". Os corpos motorizados dão sentido à cidade radial, espalhada por artérias cada vez mais desabitadas por pessoas, "estimulam o recurso dos símbolos e aos julgamentos liminares” e, por conseguinte, favorecem a segmentação da cidade: "Casa, loja, escritório, escola não só têm funções precípuas como se encontram separados por áreas vazias, facilitando a rápida avaliação sobre o comportamento dos que não pertencem ao lugar" (Sennett, 2008, p. 368).

Nesse sentido, questiona Henri Lefebvre, a rua é a desordem? Ele mesmo responde: certamente. "Todos os elementos da vida urbana noutra parte congelados numa ordem imóvel e redundante, liberam-se e afluem às ruas e por elas em direção aos centros; aí se encontram, arrancados de seus lugares fixos" (Lefebvre, 1999, p. 27). Mas ao contrário do que se pode dizer sobre o ponto de invisibilidade da rua, há o esforço de reconhecimento desse meio, de identificação de seus habitantes. Completa Lefebvre: "Essa desordem vive. Informa. Surpreende". O não-lugar é, antes, o lugar do encontro com a diferença. Sobre os encontros desencontrados da rua, a historiadora Sandra Pesavento nos ajudará ao remontar uma cena cotidiana da Porto Alegre do início do século passado: "as ruas se enchiam de gente do povo, num vaivém promíscuo de trajes e odores, que colocava lado a lado a distinta senhora que ia às compras com um descuidado cangueiro a caminho do porto" (Pesavento, 1994, p. 84). Nesse vaivém, segue Sandra, surge a figura do rueiro:

um povo sem rosto parecia habitar as ruas. Eram, em princípio, pobres, mal vestidos, muitas vezes mal-encarados e frequentemente atemorizavam a vida das famílias burguesas. A caminho do trabalho, na volta da fábrica, fazendo biscates, mendigando ou simplesmente flanando, a rua parecia lhes pertencer. (Pesavento, 1994, p. 84)

\section{Negro}

Cerca de 11 milhões de pessoas habitantes do continente africano foram sequestradas pelos europeus desde o século XVI até o XIX, transformadas em escravas no continente americano. A instituição da escravidão, diz Luiz Eduardo Wanderley (2010), moldou as sociedades no novo mundo nas suas relações jurídicas, sociais, econômicas, bem como arrimou os lugares do Estado e da Igreja. Para o Brasil, foram destinados aproximadamente $40 \%$ dessas pessoas, num volume que foi crescente até 1850, enquanto nos demais países já se vetava o tráfico de pessoas. No exemplo de São Paulo, estudado por Lia Vainer Schucman (2014), os escravos foram comprados para trabalhar principalmente nos cafezais, impulsionando a produção nacional a índices até então impensados. $\mathrm{O}$ trabalho forçado cumpria uma função econômica dentro da exportação de café para os grandes mercados europeus. Da força produtiva dos africanos se fez possível o crescimento das riquezas no país.

Esse sistema de opressão se formulou pelo conceito de raça e foi sustentado por diversas formas de violação, perpetrando a cultura, criando dissimetrias em cada relação. As consequências desse pensamento são incalculáveis. O privilégio das raças dominantes foi constituindo-se com critérios de manutenção das diferenças, exercitado, em última instância, pelo reconhecimento dos níveis de melanina que a pessoa carrega na pele. Após a abolição da escravatura, em 1884, a colocação social do negro alforriado seguiu dificultada em muitos aspectos, pois desafiava o projeto das cidades da branquitude e enunciava um dos elementos fundamentais da questão social brasileira (Wanderley, 2010). 
A solução, sustentada por uma perspectiva psicogenética, diz Lia, foi o ideal de "branqueamento" da população, uma teoria tipicamente brasileira, graduando do negro ao branco o lugar de respeito, afirmando a mestiçagem nos tons do mulato e da mulata como marca nacional. O estímulo à imigração de brancos europeus para o trabalho nas lavouras - em substituição ao trabalho negro - foi, então, uma medida insuspeita (Schucman, 2014). Frente à priorização da força produtiva branca, os negros ficavam associados à vagabundagem, ao não-trabalho, marcados como a mais baixa classe trabalhadora. Assim, diz Abdias Nascimento (1980), a concorrência por um salário submeteu o negro a uma dupla exploração: pelo capitalista industrial e pela classe trabalhadora qualificada.

Os efeitos da opressão aos negros no país se confundem com a pobreza urbana e se estendem aos nossos dias. Para Jurema Werneck, temos um Racismo Institucional, perpetuante do racismo, chamado também de Racismo Sistêmico: "garante a exclusão seletiva dos grupos racialmente subordinados", operando pelo dispositivo da racialidade, que traduz a diversidade da população negra em mecanismos de reconhecimento e exclusão, validando e elencando os privilegiados em cada relação. Para a médica (Werneck, 2016, p. 541 ), tal dispositivo penetra

nos campos da vida social e produz seus resultados, o que nos permite compreender como o racismo estrutura profundamente o escopo de democracia no Brasil, reduzindo a abrangência da cidadania por estar na base da criação e manutenção de preconceitos, ou seja, ideias e imagens estereotipadas e inferiorizantes acerca da diferença do outro e do outro diferente, justificando o tratamento desigual (discriminação).

No desenho das cidades brasileiras, o negro foi um elemento crucial para a cidade higienizada/esquadrinhada, sendo a personificação de muitos fluxos marginais, habitando uma cidadania sempre questionável, mantendo as rotas de exclusão e extermínio do Estado. Compõe as margens sociais e geográficas da urbe, desde os cortiços do centro, às "malocas" das vilas e aos barracos da rua. Não à toa se diz comumente entre os conhecedores da vida rueira: a rua tem cor.

\section{Marginal ou Morador de Rua}

A categorização como "mendigos" e "vagabundos" surgida na literatura europeia traduziu-se nas cidades modernas pela noção do lumpemproletariado ou do "trabalhador que não deu certo" (Neves, 2010). Um "resíduo social” que, recuperado na definição de Goffman por Magni (2006), se erigiu no fenômeno urbano com tamanha consistência que passou a convocar - ainda mais - as ações religiosas, as políticas de governo, as ciências sociais.

Nas primeiras cidades urbanas, a moralidade burguesa e suas técnicas tinha no lumpesinato uma estratégia de controle do mercado de trabalho e do direito à cidade. Esses sujeitos, essenciais para o mercado, tinham difícil aderência ao terreno urbano, ativando um modo de diáspora, percorrendo uma rota excludente das cidades. Segundo David Snow e Leon Anderson (1998), habitavam uma "zona marginal” do perímetro urbano, com vínculos informais destoantes da especialização exigida para o modelo industrial, vivendo de aluguéis em locais insalubres, da benemerência de entidades assistenciais: "a comida barata, os hotéis, loja de penhores e as missões da zona marginal atraíram uma população 
de derrotados, mais velhos e frequentemente deficientes, com mais de cinquenta anos em média” (p. 39). Essas zonas ficaram afamadas nas cidades por sua associação com o uso abusivo de álcool, com a prostituição, pelo flerte com a rua, em movimentos constantes de aderência e desenraizamento. $\mathrm{O}$ fenômeno do desabrigo, completam os autores, se concretizou nas cidades em torno de três pontos fundamentais: falta da habitação, literalmente; estruturação familiar (mais conforme com a vida efêmera da rua ou, noutra ponta, pela ruína dos lares burgueses); representação social (em contraponto aos papéis da moralidade e da dignidade). Essas categorias se entrelaçam de maneira dinâmica e subentendem a noção de desabrigo às falhas na constituição da habitação, da família e do trabalho.

A rua, em última instância, se torna espaço de vacância, de quem orbita fora do eixo normativo, dos que tem loucura ou coragem para não privatizar o espaço, o tempo, o corpo: reúne os descompassados com a imagem esperada, sendo a expressão pungente do que não encontra assento na cidade. A figura do habitante da rua se especializa e amplia suas margens, aprofundando o detalhamento dos desvios na medida em que se aprimoravam também os padrões de produção e consumo. Surge então um perfil multiforme, heterogêneo, fugaz e, ao mesmo tempo, constante, que surpreende por seu efeito de massa. $\mathrm{O}$ fenômeno ficou claro para o ocidente na depressão norte-americana de 1930, quando a população residual das cidades, que costumava viver em bairros de migrantes, de vínculos breves, voláteis como os negócios da cidade, assumiu uma posição de aderência mais efêmera na cidade, se especializado nas estratégias de subsistência nômades. Florestan Fernandes (1986), ao falar sobre os "desenraizados" da cidade, diz que a rua incorporou os mecanismos de exclusão presentes em outros tempos, como nos vínculos das minas de carvão, onde se mantinha uma pertença escrava ou se destinava a uma nova migração em busca de outros garimpos.

Os desenraizados assumem nas cidades o que Cláudia Turra Magni (2006) chamará de "nomadismo urbano", buscando na margem rueira uma estratégia de permanência na cidade. Pois esses fenômenos de exclusão e circulação foram aprimorados após a primeira grande crise do capitalismo, renomeando a figura que estamos estudando em "morador de rua”, assentado nas cidades em redes informais de proteção e pertença: assumem a provisoriedade da vida na rua frente a constância dos desenraizamentos do capital.

\section{Louca ou Vadia}

Às mulheres se inventou na cultura burguesa um ciclo de vida moral, como escreve Pesavento (1994), iniciado na menina doce, passando por uma amável donzela, pela esposa companheira, uma mãe educadora, chegando até a vida longa de uma avó bondosa. Essa mácula esconde muitas histórias de violências, exercidas principalmente dentro dos “doces lares”, mas articulada com os mecanismos de repressão da cidade. No caso porto-alegrense, na década de 1920, Yonissa Wadi destaca uma polícia médica sobre o feminino, com a prevalência de internações de mulheres no Hospital Psiquiátrico São Pedro e em clínicas particulares (Wadi, 2008, p. 54):

Nas interpretações médicas do início do século XX, a loucura nos homens se manifestava fundamentalmente na quebra dos papéis sociais desempenhados no espaço público, o de trabalhador ou cidadão... Nas mulheres, ao contrário, a loucura se manifestava preferencialmente na esfera privada, dominada pelas questões do corpo, da sexualidade e da família, aparecendo como mais transgressiva. 
A partir de 1923, a população interna do hospital foi predominantemente feminina, com internações mais longas que as masculinas, permanecendo sob uma tutela médico-familiar. O mesmo fenômeno é presente no Hospital Psiquiátrico do Juquery, em São Paulo, pelo que diz Maria Clementina Pereira Cunha numa pesquisa em prontuários da época, enquadrando o corpo feminino - tido como naturalmente turbulento - e a alma -- "nervosa, cíclica, excitável, presa fácil das paixões e desvarios, de poucos pendores intelectuais, de sensibilidade à flor da pele e sujeita a todo tipo de perturbação da razão que, em última instância, decorriam de sua própria 'instabilidade' corporal” (Cunha, 1989, p. 130).

Não será, entretanto, uma categoria aplicável ainda às mulheres proletárias, de rua, negras. Destina-se essencialmente aos lares da crescente burguesia, praticado dentro da família, em defesa de um modelo de mulher higiênica e moderna, "mãe de família, educadora, nutriz, moderadora dos ímpetos masculinos, cúmplice da medicina na prescrição de normas higiênicas, elo de coesão da esfera familiar, chefe na economia doméstica e na contabilidade dos afetos, fonte de estabilidade dos filhos e do marido" (Cunha, 1989, p. 131). Às mulheres de classes sociais "inferiores", se destinava um tratamento diferenciado, sustentado mormente pelas teses da degenerescência que indicavam uma falta de moralidade nas transmissões de famílias pobres, viciadas, vagabundas.

As mulheres que exerciam a prostituição foram incluídas na série da transgressão das ruas, assimilando também o discurso da higiene social e a imagem de afronta à família. Em Porto Alegre, esse era um tema recorrente quando se referia às vidas desajustadas. No antigo Beco do Poço, onde funcionavam os bordéis de Fausta e Domingas, eram comuns os causos de morte, beberagem, de aliciamento de crianças e toda ordem de atos vis. A manchete era sempre de apuro, de impacto, acusando o perigo dos personagens em cena. A "puta” era avessa ao modelo patriarcal constituído, que atribuía às mulheres um lugar ao mesmo tempo encantador e funcional. A profissão acolhia de alguma maneira as desescalonadas do ciclo moral esperado, imagem de uma vida desregrada, sendo vasta sua fama: "desencaminhavam a juventude, pervertiam crianças, seduziam pais de família, viviam cercadas de bêbados e jogadores" (Pesavento, 1994, p. 134). A "vadia”, avesso da mulher idealizada pela cultura, se assumiu como uma das caras do perigo urbano, habitando muitos vazios deixados pela cidade, vãos e esquinas sombreadas pelos holofotes dos códigos médico-policiais.

\section{Maloqueiro}

Em Porto Alegre, a casa-cortiço, entranhada nas vielas do centro da cidade, foi considerada como o avesso do padrão familiar e se tornou alvo fácil dos códigos de posturas e das comissões de saneamento. O espaço era visto como foco de infecções, origem dos miasmas, que podiam espalhar-se por toda a cidade; foco também de vidas promíscuas, de relações de trabalho informais, de perigo social. Os casebres foram varridos em movimentos de segregação da cidade, acusados de inadequação às condições de salubridade exigidas pelas leis da intendência. Um jornal da época retratou bem o pensamento: "Mas onde irá morar esta gente pobre? É fácil a resposta (...). Os arrabaldes estão aí e devem ser habitados pelos proletários. Na cidade propriamente dita, só devem residir os que podem sujeitar-se às regras e preceitos da higiene" (Gazeta da Tarde, 17 jan. 1898, citado por Pesavento, 1994, p. 96). 
O crescimento das vilas deu-se se deu, além do movimento de segmentação da cidade, pelo movimento de êxodo rural. Segundo Magni (2006), a urbanização gerou uma oferta de mão de obra excessiva, provocando o rebaixamento dos salários e o aprimoramento do setor terciário de biscates e subempregos. As novas "regiões problema" - instaladas nos pontos menos nobres e salubres da cidade - são identificadas, já em 1940, como "vilas de malocas", nomeação feita pelo sociólogo Laudelino Teixeira de Medeiros nos seus Ensaios sobre sociologia urbana, de 1951 . Na obra, o autor usa os dados da prefeitura para falar das 4.558 malocas e mais de 15.000 almas distribuídas nos arrabaldes, todos habitantes dessa zona indefinida de pertença: "Economicamente, os habitantes dessas vilas pertencem às camadas inferiores, com agravante de uma percentagem mais elevada de desajustados, de miseráveis e indigentes (Medeiros, 1951 citado por Magni, 2006, p. 29).

Os territórios negros, em especial, foram objeto da política branqueadora da cidade. A Ilhota, o Areal da Baronesa e a Colônia Africana são exemplos porto-alegrenses dessa urbanidade que se formava através da organização social da população negra, adensada adiante pelos migrantes, os desempregados e demais excedentes da norma burguesa. Com o crescimento da cidade e a ampliação do centro produtivo, essas malocas também foram varridas. As remoções foram feitas das áreas baixas e calamitosas, saneadas pelas políticas de drenagem e pavimentação, transladando as pessoas para pontos remotos - verticais: morros; horizontais: restingas e banhados - da cidade.

As primeiras políticas habitacionais do Estado brasileiro foram destinadas aos trabalhadores assalariados, afiançados por contratos sociais que a nação assinaria, com o financiamento direto de casas populares. Numa perspectiva desenvolvimentista, portanto, os setores da construção civil se aliaram ao Estado para fazer da questão habitacional uma estratégia econômica e moral. O "sonho da casa própria" deu vazão aos empreendimentos imobiliários e, noutro plano, implementou os conceitos de uma cidade limpa e moderna. Diz Maria Silva Barros Lorenzetti (2006) que o fato de dar posse de uma casa gerava uma incumbência ao sujeito de zelar pelo patrimônio material e, ao mesmo tempo, cultivar as boas condutas comunitárias, manter a ordem, sendo mais um elemento de estabilização social. Na ditadura militar, com a criação do Banco Nacional de Habitação, as desapropriações se tornaram definitivamente uma política pública. O BNH tinha como lema: "remover para promover".

A invenção do bairro Restinga em Porto Alegre, em 1966, foi concomitante a essa política, deslocando comunidades que habitavam pontos desejados pela classe média burguesia e objeto da especulação imobiliária (Zamboni, 2009). Com a canalização do arroio Dilúvio, os "melhoramentos" feitos no entorno do Caminho do Meio, as áreas se tornaram de "utilidade pública ou social” e, assim, a cidade empurrou mais uma vez a população dita insalubre, afamada por uma vida infernal, de brigas, imoralidades, promiscuidades. A Ilhota foi renomeada como Menino Deus, a Colônia Africana como Rio Branco (Pesavento, 2001). Sob o argumento divino e branqueador, portanto, a população negra, pobre, desempregada, teve que ceder os seus tetos conquistados para viver em outra zona segregada da cidade.

A questão habitacional se expressou nas cidades justamente na contra-imagem da casa higienizada, da família econômica, do trabalho digno. De fato, interroga: de quem é a cidade? Ou ainda: quais os limites da cidade? Quais os limites da vida ordenada? A explicação escapa em toda tentativa de resposta. 


\section{Em Massa}

O fenômeno das ruas foi matéria constante das Ciências Sociais modernas, assimilada como uma patologia social, sendo explicada de muitas formas. Para Rosane (2005), o movimento das massas urbanas evidenciaram um efeito da dobra capitalística, transpondo o enquadre disciplinar e geográfico para um enquadre subjetivo das existências: em vez de uma desterritorialização geográfica, uma distonia identitária. Assim, a desterritorialização "sem sair do lugar" dessas populações trouxe à visibilidade os desenraizamentos da cidade, pondo em questão o direito à cidade, movimentando saberes e poderes. Em dissimetria, o estudo dos coletivos enfatizou os aspectos individuais, atrelados indissociavelmente à transmissão genética e cultural das famílias. Seguindo com Rosane, "se institui uma nova relação entre o indivíduo e a massa: ao mesmo tempo em que a massa não é mais considerada como uma soma de indivíduos, o indivíduo é tomado como modelo para compreender o fenômeno das massas" (2005, p. 64). A psicologia social, nascida do determinismo entre indivíduo e sociedade, é fruto de um "problema mal colocado", diz Rosane Silva (2005). Ao analisar a ação psi no contexto das políticas sociais, percebe-se uma relação muito próxima entre as disfunções sociais e as psicopatologias ou quadro de vulnerabilidades e riscos. A psicologização e a biologização dos indivíduos alvos das políticas fundamenta muito das compreensões sobre o fenômeno da rua, somando-se aos sentidos da martirização religiosa que secularmente já acompanham os desfiliados.

Os códigos da arquitetura, da economia, da epidemiologia médico-estatística, formulam uma certa ciência da cidade, forjando saberes e práticas, criando políticas sociais nas simetrias do poder vigente. Formam-se assim formações discursivas sobre os elementos que se colocam em série, perfilando os personagens e tipos psicossociais, circunscritos dentro de curvas "normais" de ocorrência. No curso Segurança, Território e População (1977-1978), Michel Foucault diz que na técnica de gestão da urbe "o que vai se procurar atingir por esse meio é precisamente o ponto em que uma série de acontecimentos, que esses indivíduos, populações e grupos produzem, interfere com acontecimentos de tipo quase natural que se produzem ao redor deles" (Foucault, 2008a, p. 28). O governo das cidades deve prever o que tangencia os índices esperados - tanto para a produção quanto para a conduta -, sendo o excedente - de trabalho ou de sociabilidade -, uma incógnita dos códigos. Esses restos, híbridos por essência, movimentam a trama assistencial que toma o sujeito moderno, contraditoriamente, como um caso individual. Os que permanecem na vida "selvagem", que não se docilizam, serão justamente os sujeitos alvo das políticas do Social.

Entre o trabalhador padrão e o desempregado, entre o cidadão de direitos e o desassistido, entre a sobrevivência e o desvio, portanto, o Estado e seu aparelho normativo passa a intermediar a questão social numa relação institucional-indivíduo: entre a polícia e o vivente da rua, a filantropia e a criança abandonada, a medicina e o débil. Nesse campo medial, habitado por códigos da norma, se faz a inspeção sobre a categoria em que o sujeito se encaixa e o devido tratamento. Sabemos que esse exercício é inglório: o desviante não faz desvios, ele é apenas desviante. A matemática só fez aumentar os inclassificáveis.

Essas técnicas juntas operam o que Michel Foucault (2002) chama das bases da "biopolítica”, ingressando nas famílias pela medicina social, pela dobra das técnicas disciplinares para dentro das casas. Desse modo, amplia-se o estado de segurança para toda a sociedade, cabendo ao saber médico-policial os hábitos menores de cada família e de cada 
indivíduo. De um modo bastante esquemático, Foucault (2008a, p. 16) diz: "a soberania se exerce nos limites de um território, a disciplina se exerce sobre o corpo dos indivíduos e, por fim, a segurança se exerce sobre o conjunto de uma população”.

Para o Estado moderno, enfim, não interessa tratar de uma multiplicidade de indivíduos, pois assim daria margem às singularidades de cada sujeito, preferindo a noção de população enquanto totalidade. Com essa noção, forja-se o objeto e também as políticas para obter resultados específicos com o mesmo. Num franco empirismo, ao corpo individual se aplicam testes em máquinas disciplinares, se escalonam os fenômenos, se classificam os tipos sociais, se separam os corrigíveis dos perdidos. A população como dado estatístico, nessa massificação, sujeita as pessoas aos saberes e às práticas de individualização dos corpos.

\section{Em Situações}

Segundo a tipologia da European Federation of National Organisations Working with the Homeless (FEANTSA), as categorias do desabrigo seriam: Sem Teto (a viver em espaço público ou alojado em abrigo de emergência), Sem Casa (a viver em Centros de Acolhimento, Alojamentos, Casas-Abrigo), Habitação Insegura (a viver em espaços temporários, sem arredamento legal, ameaçados de despejo, vítimas de violência doméstica), Habitação Inadequada (estruturas temporárias, ocupações ilegais de terrenos e prédios, alojamentos sem condições ou não adequados, sobreocupações) (Secretaria de Direitos Humanos, 2013). Enquanto no Brasil o número da rua se refere, mormente, a pessoas sem teto e sem casa, em outros países o homeless, o Sans Domicile Fixe, as personas sin hogar, são medidas em categorias diversas, indeterminando o que se refere a rua estritamente ou também às sub-habitações da cidade.

A questão brasileira da rua não surge, então, como uma questão habitacional ou proletária. Por outro lado, foca-se na vida rueira, atentando para a heterogeneidade das pessoas que vivem na rua. No Brasil do final do século passado, o Estado definiu políticas públicas específicas para essa população, com instrumentos de monitoramento sobre seu crescimento demográfico, sobre os seus perfis, de modo a estabelecer estratégias de cuidado e controle. Uma produção relevante foi, em 1992, o livro População de Rua: quem é, como vive, como é vista, organizado pela prefeitura de São Paulo a partir da análise de vários pesquisadores (Vieira, Bezerra, \& Rosa, 1992). Eram os primeiros anos da "República Cidadã" de 1988 e justamente se exercitavam os conceitos de uma cidadania plena, razão pela qual as pessoas moradoras da rua passaram a ser reconhecidas como pessoas de Direito. O texto situa a população de rua como um segmento da classe trabalhadora, acrescida pela recessão econômica dos anos 1980, formada no revés do trabalhador formal (Vieira et al., 1992). Tinham uma relação diversa com a rua, categorizada pelos pesquisadores da seguinte forma: ficar na rua (circunstancialmente), estar na rua (recentemente) e ser da rua (permanentemente). Negociam cotidianamente as formas de viver na rua: "sua vida está sempre começando. Quase nada é permanente, a não ser a procura cotidiana da sobrevivência, o que torna sua vida extremamente fragmentada” (Vieira et al.,1992, p. 22). A experiência fica assim repartida em pequenas negociações diárias, escondendo muitos processos de exclusão e violência, tornando a miséria um espetáculo urbano bastante presente nas microrrelações da cidade. 
Na etnografia feita no início dos anos 1990 por Cláudia Turra Magni em Porto Alegre, intitulada Nomadismo Urbano, a antropóloga encontrou nas ruas um perfil de morador itinerante, com alguns pontos de ancoragem acionados de acordo com os movimentos da vida, da fome, do prazer, do medo, do sono, das amizades. No estudo, Magni mapeou diversos acampamentos dos habitantes da rua, formados em "viadutos, vias elevadas, pontes, parques, largos, praças, calçadas e praias, além de algumas propriedades particulares abandonadas, como estruturas inacabadas, prédios e terrenos baldios" (Magni, 2006, p. 32), frequentado por pessoas vinda mormente do interior do Estado e das favelas metropolitanas, intercalando a rua com sub-habitações de conhecidos ou familiares. A mobilidade da rua desafiava o modo sedentário da cidade, afirmada num circuito territorial e existencial.

A partir dos anos 2000, a "população em situação de rua” se consolida como categoria separada das demais mazelas da cidade, afirmada como questão fundamental de qualquer grande urbanidade. O conceito de situacionalidade atesta a pluralidade das situações que levam à rua e, no revés, conforme Patrice Schuch e Ivaldo Gehlen (2012), representa uma ruptura com os termos "morador de rua" ou "sofredor de rua", que produziam uma noção estigmatizada e generalizadora do fenômeno. Os censos da rua se espalham pelas capitais do país, sendo tentada uma contagem nacional em 2009, no documento "Rua, aprendendo a contar", organizado pelo Ministério do Desenvolvimento Social e Combate à Fome. Ao todo, contou cerca de 32 mil pessoas, reconhecendo a rua como uma categoria difusa. Segundo Marco Antônio Carvalho Natalino (2016), no texto para discussão do Instituto de Pesquisa Economia Aplicada (IPEA) em 2016, a estimativa da população de rua no país para aquele ano passava dos 100 mil.

Nessa matemática, escapam números invisíveis, palavras, códigos, histórias e estórias sobre uma vida infinitesimal. Entre as casas decimais, centésimas, milésimas, milionésimas correm números "fora da casa", propôs-se arranjos não simétricos, contas que não dão o resultado certo e que desafiam qualquer álgebra ou conceito.

\section{Desenquadres}

No centro, no coração da representação, o mais próximo do que é essencial, o espelho que mostra o que é representado, mas como um reflexo tão longínquo, tão imerso num espaço irreal, tão estranho a todos os olhares que se voltam para outras partes que não é mais do que a mais frágil reduplicação da representação. (Foucault, 2011, p. 424)

Pelo fundo da figura, o alvo escapa logo adiante do olhar, causando incômodo pela própria condição de ser inapreensível ou inassimilável. A "População em Situação de Rua”, nesse sentido, ocupa uma posição semelhante a do rei no quadro de Velásquez, analisado por Foucault (2011). Prenhe de enquadres e representações, marcada pelo estigma de um padrão de vida social. Do outro lado do espelho e por toda a tela, os habitantes da rua afirmam um cotidiano doméstico na cidade, de existências que visam não somente a sobrevivência material e afetiva, mas o respeito e a convivência em grupo, a liberdade do isolamento ou da loucura, a possibilidade de viver os excessos e os descasos com a vida. Nessa lente, vemos o afeto, os vínculos, as relações que se fortificam na rua. 
É preciso, portanto, estratégia, para o estudo dessa matéria indefinida. Uma postura que se assemelha, no cerzir, com o exercício do cartógrafo, recolhendo fragmentos de todas as partes, absorvendo, como diz Rolnik (2011), "matérias de qualquer procedência" (p. 65), acompanhando as paisagens conforme elas se formam e se desfazem. Com esse orientador, antes da análise de um campo etnográfico ou histórico, colocamos a imagem em fundo, em movimento às "paisagens psicossociais", acusando uma constante presentificação da vida, submetendo o passado e o futuro a registros esotéricos. Os recortes utilizados nesse texto funcionam, enfim, como frases de uma discursividade maior, assumem uma forma estética na tessitura de uma malha de forças, sendo muito mais ilustrativo do que representativo.

Tivemos em grande medida como inspiração o método genealógico de Michel Foucault (2008b), que aposta numa narrativa intempestiva, amparando-se numa arqueologia dos enunciados da questão social na cidade, acompanhando fragmentos de uma história deixada pelo caminho. A genealogia incorpora aos arquivos os afetos, as tensões, as opressões, permitindo um estudo sobre as relações de poder que modulam a vida-norma e a vida-desvio. O método não se opõe à história enquanto ciência geral, exceto no ponto em que se propõe à formatação de verdades, de construção de continuísmos ou etapas evolutivas. A imagem de um tecido inteiriço e puro é uma marca do mundo moderno, sendo sempre sobreposta por revoluções tecnológicas que instauram mais adiante um saber inovado, inventando classificações que só fazem proliferar as partículas hibridas.

Para Gilles Deleuze e Félix Guattari (2010), os planos de existência são movimentados por "personagens conceituais", agentes da enunciação das regras do platô, assumindo uma impessoalidade que não produz corpos ou territórios, mas move sentidos num plano de composição dos afetos e dos enunciados. Os “tipos psicossociais”, por sua vez, serão a personificação das tramas enunciativas, presente nas "circunstâncias mais insignificantes ou mais importantes", com o sentido de "tornar perceptíveis as formações de territórios, os vetores de desterritorialização, o processo de reterritorialização" (Deleuze \& Guattari, 2010 , p. 83). Rosane Silva (2005) entende que estes expressam as forças que operam num campo de práticas, atualizando as problemáticas do campo socio-histórico em novas superfícies, novos tempos, novos corpos.

Trazendo para a discursividade da rua, os habitantes da "situacionalidade" formam uma superfície de contato com a cidade que só poderia ser entendida em movimento, pois forma-se por partículas assimétricas, por discursos controversos, por tempos distintos, por práticas difusas. Em deflexão à imagem da "pessoa em situação de rua" - forjada pelas insignes do nômade, do desgraçado, do mendigo, do vagabundo, do rueiro, do negro, do marginal, da louca, da vadia, do maloqueiro, do andarilho, do morador de rua - queremos também enunciar o personagem que habita cotidianamente as bordas da cidade, afirmando um projeto de vida com estratégias, com os vínculos possíveis, afirmando laços perenes em meio a efemeridade da cidade. São os não-ditos da rua: solidário, fraterno, trabalhador, empreendedor, professor, escritor, gregário, amigo, amante, protetor, militante, cidadão, e todos os silenciamentos como etc.

Ao "anti-cidadão", muitas políticas foram inventadas desde que as cidades se tornaram polos de trabalho e proteção, com seus regimes de utilidade e subserviência, banindo, matando e prendendo desde o mundo antigo; internando, corrigindo, reeducando desde os tempos modernos. No Brasil e em todo continente americano, a rua está marcada por eixos transversais que buscamos evidenciar, nos preconceitos de raça, gênero e classe social, alvos em todas as séries de uma intersecção de poderes. De forma manifesta, a cidade 
expande o capital com novas tecnologias, novas velocidades, ao mesmo tempo em que intensifica a higiene social, a moral disciplinar, o branqueamento, a docilidade: segrega. No plano urbano, o direito à cidade é negado não apenas aos habitantes da rua, mas se estende aos demais desabrigados da cidade, que vivem em "áreas verdes", "invasões”, ocupações, sub-habitações: todos alvo constante das políticas de remoção.

No limite, a rua acolherá muitos dos nomes malditos ou não-ditos da cidade. A provisoriedade ou a situacionalidade do assentamento na rua é, antes, uma regularidade presente nas grandes cidades. A vida rueira afirma, frente ao desamparo vivido, um modo de vida urbano, habitando a cidade em seus restos, espaços ocos, invisíveis, sustentando-se das efemeridades, com laços de proteção instáveis e tênues, que são tão facilmente rompidos quanto refeitos, negociando cotidianamente sua cidadania.

\section{Referências}

Castel, R. (2015). As metamorfoses da questão social: uma crônica do salário. Petrópolis, RJ: Vozes. Cunha, M. C. P. (1989). Loucura, Gênero Feminino: As mulheres do Juquery na São Paulo do início do Século XX. Revista Brasileira de História, 9(18), 121-144.

Deleuze, G. \& Guattari, F. (2010). O que é filosofia. São Paulo: Editora 34.

Fernandes, F. (1986, 21 de agosto). Os desenraizados. Folha de São Paulo, p. 3.

Foucault, M. (2002). Os Anormais. São Paulo: Martins Fontes.

Foucault, M. (2008a). Segurança, Território, População. São Paulo: Martins Fontes.

Foucault, M. (2008b). Arqueologia das ciências e história dos sistemas de pensamento. Rio de Janeiro: Forense Universitária.

Foucault, M. (2011). As palavras e as coisas. São Paulo: Martins Fontes.

Geremek, B. (1995). Os filhos de Caim: vagabundos e miseráveis na literatura europeia: 14001700. São Paulo: Companhia das Letras.

Lefebvre, H. (1999). A revolução urbana. Belo Horizonte: Editora UFMG.

Lorenzetti, M. (2006). A questão habitacional no Brasil. Brasília, DF: Câmara dos Deputados.

Magni, C. T. (2006). Nomadismo Urbano: uma etnografia sobre moradores de rua em Porto Alegre. Santa Cruz do Sul, RS: EDUNISC.

Ministério do Desenvolvimento Social e Combate à Fome. (2009). Rua: aprendendo a contar: Pesquisa Nacional sobre a População em Situação de Rua. Brasília, DF: Autor.

Mollat, M. (1989). Os pobres na Idade Média. Rio de Janeiro: Campus.

Mumford, L. (1998). A cidade na história: suas origens, transformações e perspectivas. São Paulo: Martins Fontes.

Nascimento, A. (1980). O quilombismo. Petrópolis, RJ: Vozes.

Natalino, M.A. C. (2016). Estimativa da população em situação de rua no Brasil. Brasília, DF: Instituto de Pesquisa Econômica Aplicada; Rio de Janeiro: IPEA.

Neves, D. P. (2010). Habitantes da rua e vicissitudes do trabalho livre. Revista Antropolitica, 29, 99-130. 
Pesavento, S. (1994). Os pobres da cidade: vida e trabalho - 1888-1920. Porto Alegre: Editora da UFRGS.

Pesavento, S. (2001). Uma outra cidade: o mundo dos excluídos no final do século XIX. São Paulo: Companhia Editora Nacional.

Rolnik, S. (201 1). Cartografia sentimental: transformações contemporâneas do desejo. Porto Alegre: Sulina; Editora da UFRGS.

Schuch, P. \& Gehlen, I. (2012). A "situação de rua" para além de determinismos: explorações conceituais. In A. Dorneles, J. Obst, \& M. S. Borba (Orgs.), A rua em movimento (pp. 11-25). Belo Horizonte: Didática.

Schucman, L. V. (2014). Entre o encardido, o branco e o branquíssimo. São Paulo: Annablume.

Secretaria de Direitos Humanos. (2013). Diálogos sobre a população de rua no Brasil e na Europa. Brasília, DF: Autor.

Sennett, R. (2008). Carne e Pedra: o corpo e a cidade na civilização ocidental. Rio de Janeiro: Bestbolso.

Silva, R. N. (2005). A invenção da Psicologia Social. Petrópolis, RJ: Vozes.

Snow, D. A. \& Anderson, L. (1998). Desafortunados: um estudo sobre o povo da rua. Petrópolis, RJ: Vozes.

Stoffels, M. (1977). Os mendigos na cidade de São Paulo: ensaio de interpretação sociológica. Rio de Janeiro: Paz e Terra.

Vieira, M. A. C., Bezerra, E. M. R., \& Rosa, C. M. M. (Orgs.). (1992). População de Rua: quem é, como vive, como é vista. São Paulo: Editora Hucitec.

Wadi, M. Y. (2008). Médicos e loucos no sul do Brasil: um olhar sobre o Hospício São Pedro de Porto Alegre/RS, seus internos e as práticas de tratamento da loucura (18841924). Revista de Historia de la Medicina y de la Ciencia, LX(2), 43-74.

Wanderley, L. E. (2010). A questão social no contexto da globalização: o caso latino-americano e o caribenho. In M. Belfiore-Wanderley, L. Bógus, \& M. C. Yazbec (Orgs.), Desigualdade e a questão social (pp. 55-166). São Paulo: EDUC.

Werneck, J. (2016). Racismo Institucional e saúde da população negra. Saúde e Sociedade, 25(3), 535-549.

Zamboni, V. (2009). Construção social do espaço, identidades e territórios em processos de remoção: o caso do bairro Restinga - Porto Alegre/RS. Dissertação de Mestrado, Programa de Pós-graduação em Planejamento Urbano e Regional, UFRGS, Porto Alegre, RS. 


\section{MATEUS FREITAS CUNDA \\ https://orcid.org/0000-0002-6659-6308}

Psicólogo com Mestrado e Doutorado em Psicologia Social e Institucional pela Universidade Federal do Rio Grande do Sul. Como municipário de Porto Alegre, trabalha na Secretaria Municipal de Saúde, no Centro de Atenção Psicossocial Álcool e Drogas (CAPS AD) na região Glória/Cruzeiro/Cristal. Endereço: Rua São Vicente, 513/303, Santa Cecília, Porto Alegre, RS, CEP 90630-180.

E-mail: mateuscunda@yahoo.com

\section{ROSANE NEVES SILVA}

http://orcid.org/0000-0001-6486-0630

Professora titular do Instituto de Psicologia da Universidade Federal do Rio Grande do Sul. Possui Graduação em Psicologia, Especialização em Psicologia Escolar, Mestrado em Psicologia Social e da Personalidade e Doutorado em Educação.

E-mail: rosane.neves@,ufrgs.br

\begin{tabular}{|l|l|}
\hline \multirow{3}{*}{ Histórico } & Submissão: 12/05/2019 \\
& Revisão: 19/08/2019 \\
& Aceite: 16/09/2019 \\
\hline \multirow{3}{*}{ Contribuição } & Concepção: M.F; R.N. \\
& Coleta de dados: M.F. \\
& Análise de dados: M.F; R.N. \\
& Elaboração do manuscrito: M.F. \\
& Crítico revisões de conteúdo intelectual importante: \\
& M.F; R.N. \\
& Final aprovação do manuscrito: R.N. \\
\hline \multirow{2}{*}{ Financiamento } & Não houve financiamento. \\
\hline
\end{tabular}

